\title{
Management of patients with disk displacement without reduction of the temporomandibular joint by arthrocentesis alone, plus hyaluronic acid or plus platelet-rich plasma
}

\section{Leczenie pacjentów z przemieszczeniem krążka stawowego z zablokowaniem stawu skroniowo-żuchwowego wyłącznie przez artrocentezę lub dodatkowo z kwasem hialuronowym lub osoczem bogatopłytkowym}

\author{
Mahmood Hasan Toameh ${ }^{1, A, D, F}$, Issam Alkhouri ${ }^{1, A, F}$, Mohammed Ammar Karman ${ }^{2, A-C}$ \\ ${ }^{1}$ Department of Oral and Maxillofacial Surgery, Faculty of Dental Medicine, University of Damascus, Syria \\ ${ }^{2}$ National Dental Center for Syrian board and specialization, Damascus, Syria \\ A - research concept and design; $\mathrm{B}$ - collection and/or assembly of data; $\mathrm{C}$ - data analysis and interpretation; \\ $D$ - writing the article; $E$ - critical revision of the article; $F$ - final approval of the article
}

Address for correspondence
Mahmood Hasan Toameh

E-mail: mahtoameh@gmail.com

Funding sources

None declared

Conflict of interest

None declared

Received on March 13, 2019

Reviewed on April 24, 2019

Accepted on May 13, 2019

Published online on September 30, 2019

Cite as

Toameh MH, Alkhouri I, Karman MA. Management of patients with disk displacement without reduction of the temporomandibular joint by arthrocentesis alone, plus hyaluronic acid or plus platelet-rich plasma. Dent Med Probl. 2019;56(3):265-272. doi:10.17219/dmp/109329

DOI

10.17219/dmp/109329

Copyright

๑ 2019 by Wroclaw Medical University

This is an article distributed under the terms of the

Creative Commons Attribution 3.0 Unported License (CC BY 3.0)

(https://creativecommons.org/licenses/by/3.0/)

\begin{abstract}
Background. Disk displacement without reduction (DDwoR) is one of the most common temporomandibular joint disorders (TMDs); it can manifest itself in joint pain and limited mouth opening. Nowadays, many arthrocentesis techniques are used with no consensus on which technique is optimal.

Objectives. The aim of this study was to investigate the efficacy of 3 techniques in the treatment of TMD known as DDwoR and to compare them in order to determine whether one is superior to the others.

Material and methods. A prospective study was conducted between May 2015 and June 2018. The sample consisted of 30 adult patients ( 6 males and 24 females; mean age: $38.87 \pm 6.40$ years) with DDWoR, confirmed with magnetic resonance imaging (MRI). The patients were randomly divided into 3 groups according to the treatment technique applied: arthrocentesis only (control); arthrocentesis plus hyaluronic acid (HA); and arthrocentesis plus platelet-rich plasma (PRP). The maximum mouth opening (MMO) as well as pain intensity and masticatory efficiency on a visual analog scale (VAS) were measured at the time of diagnosis (baseline) and at 1-month, 3-month, 6-month, and 9-month follow-up appointments. The significance level was set at 0.05 for all statistical tests.

Results. The 3 techniques resulted in significant improvement in MMO and all VAS parameters. The one-way analysis of variance (ANOVA) revealed significant differences $(p<0.05)$ in the variables between the 3 groups. The increase in MMO in the PRP and HA groups was significantly greater than in the case of the control group, whereas no significant difference was found between the PRP and HA groups. The pain intensity and masticatory efficiency results were significantly better in the PRP group than in the HA group or the control group; at the same time, no significant differences were noted between the HA group and the control group.

Conclusions. Despite the fact that patients benefited from all of the 3 techniques, arthrocentesis plus PRP appeared to be superior to arthrocentesis plus HA or arthrocentesis alone.
\end{abstract}

Key words: temporomandibular joint disorders, temporomandibular joint arthrocentesis, platelet-rich plasma, hyaluronic acid

Słowa kluczowe: zaburzenia stawu skroniowo-żuchwowego, artrocenteza stawu skroniowo-żuchwowego, osocze bogatopłytkowe, kwas hialuronowy 


\section{Introduction}

Disc displacement without reduction (DDwoR) accounts for $35.7 \%$ of temporomandibular joint disorders (TMDs). ${ }^{1}$ The articular disc is displaced relative to the condyle when the mouth is open or closed, and the symptoms include severe pain in the temporomandibular joint (TMJ), limitation of mouth opening and, in unilateral displacements, deviation of the mandible to the painful side. ${ }^{2}$

The pathogenesis of this temporomandibular joint dysfunction has pointed to biochemical factors, separate from the disc displacement theory. ${ }^{3}$ For example, inflammatory reactions that occur in TMJ are essential for the development and progression of the disease, including high levels of inflammatory mediators in the synovial fluid, such as interleukin 1 beta (IL-1 $\beta$ ), tumor necrosis factor alpha (TNF- $\alpha$ ) and others. Furthermore, the disintegration of the important component of the synovial fluid - hyaluronic acid (HA) - leads to a decrease in the viscosity of the synovial fluid and the deterioration of the joint proteoglycan matrix. ${ }^{4}$

Additionally, many researchers have stated that increased friction of the articulating surfaces might be a pivotal cause of the articular disk displacement. Therefore, in any suggested procedure, the abovementioned pathologies must be taken into consideration. ${ }^{5}$

Many conservative approaches have been proposed throughout the years, including occlusal splint therapy, ${ }^{6}$ physical therapy, ${ }^{7}$ pharmacotherapy, ${ }^{8}$ and arthrocentesis. Nitzan et al. first described TMJ arthrocentesis as the simplest form of surgery aiming to remove the inflamed synovial fluid from the joint space, restore the viscosity of the synovial fluid and get rid of the adhesions by applying hydraulic pressure. ${ }^{9}$ It is considered the first surgical choice in patients who do not respond to conservative treatment. ${ }^{10}$

Later, many arthrocentesis techniques have been developed; some studies have mentioned the benefit of additional medication following arthrocentesis, e.g., with corticosteroids, HA and platelet-rich plasma (PRP).

Intra-articular HA preparations are widely used in orthopedics for their curative effects, such as reducing pain, ${ }^{11}$ lubricating the joint surfaces, preventing degeneration by decreasing friction, and providing cushioning to absorb pressure and vibration. ${ }^{12}$

On the other hand, the primary advantage of PRP treatment is the topical administration of platelet-derived growth factors (PDGFs), which are involved in healing and regenerating the damaged tissue as well as regulating inflammatory mediators ${ }^{13}$ and stimulating the HA synthesis. ${ }^{14}$

The medical literature is abundant in studies on the optimal procedure for dealing with TMDs. Therefore, the aim of the present study was not just to evaluate the efficacy of 3 techniques in the treatment of TMJ DDwoR, but also to compare them in order to determine whether arthrocentesis plus PRP is superior to arthrocentesis plus HA or arthrocentesis only.

\section{Material and methods}

\section{Study design}

A prospective study with a 9-month follow-up period was conducted between May 2015 and June 2018 at the Department of Oral and Maxillofacial Surgery, Faculty of Dental Medicine of the University of Damascus, Syria.

This study was carried out with the approval of the university Ethics Committee at the Ministry of Higher Education of Syria (protocol No. 1394), and written informed consent was obtained from all the patients.

\section{Sample size estimation}

The required sample size was calculated using the $\mathrm{G}^{*}$ power software v. 3.1.8 (Heinrich Heine University, Düsseldorf, Germany) using the following assumptions in accordance with a study by Hegab et al. ${ }^{15}: \alpha=0.05$; study power: $90 \%$; and effect size: 0.85 . Twenty-seven patients were required, so 30 patients (10 patients in each group) were enrolled in the current study to avoid attrition affecting the results.

\section{Patient selection}

Patients were selected from a large group admitted to the Department of Oral and Maxillofacial Surgery, Faculty of Dental Medicine of the University of Damascus, Syria, who had been clinically and radiologically (magnetic resonance imaging - MRI) diagnosed with unilateral TMJ DDwoR. All patients had been unsuccessfully treated using conservative therapies (pharmacotherapy, soft diet, jaw exercises, or occlusal splint therapy) for at least 3 months.

The study sample included 30 adult patients -6 males (20\%) and 24 females (80\%) - and their mean age was $38.87 \pm 6.40$ years.

The inclusion into the study was based on the diagnosis of DDwoR with limited mouth opening according to the Diagnostic Criteria for Temporomandibular Disorders (DC/TMD) ${ }^{16}$ as follows:

- clinical criteria:

- the jaw locked so that the mouth does not open wholly,

- the limitation in jaw opening severe enough to interfere with the ability to eat,

- the maximum assisted opening (passive stretch) movement, including vertical incisal overlap, $<40 \mathrm{~mm}$;

- radiological criteria:

- in the maximum intercuspal position, the posterior band of the disk located anterior to the $11: 30$ position and the intermediate zone of the disk anterior to the condylar head,

- at full opening, the intermediate zone of the disk located anterior to the condylar head. 
The exclusion criteria comprised patients with systemic diseases (rheumatoid arthritis, psoriatic arthritis and juvenile arthritis) or who had received treatment with anticoagulants.

According to the undertaken arthrocentesis technique, the patients were randomly assigned to 1 of the 3 following equal groups (Table 1 ):

- group I - patients receiving arthrocentesis with $100 \mathrm{~mL}$ of Ringer's lactate solution only (control group);

- group II - patients receiving an intra-articular injection of $1 \mathrm{~mL}$ of HA following arthrocentesis with $100 \mathrm{~mL}$ of Ringer's lactate (HA group);

- group III - patients receiving an intra-articular injection of $1 \mathrm{~mL}$ of PRP following arthrocentesis with $100 \mathrm{~mL}$ of Ringer's lactate (PRP group).

\section{Outcome measurements}

The preoperative maximum mouth opening (MMO) was measured in $\mathrm{mm}$ as the distance between the incisal edge of the upper and lower central incisors. The visual analog scale (VAS; range: $0-10$ ) values for pain intensity and mastication efficiency were recorded. For the pain intensity assessment, the scale ranged from 0 , representing no pain, to 10 , representing the worst imaginable pain. For masticatory efficiency, the scale ranged from 0 - eating only liquid foods, to 10 - eating any solid and/or hard foods. ${ }^{17}$ These clinical parameters were assessed by the same operator at the time of diagnosis (baseline) and at each follow-up appointment (1-month, 3-month, 6-month, and 9-month).

\section{Injection technique}

Intravenous sedation was performed in order to gain complete control of the pain, and then the skin surface was disinfected with povidone iodine. Once the joint was locally anesthetized, 2 points were marked over the glenoid fossa and the articular eminence along the canthal -tragus line (Holmlund-Hellsing line), similar to the entry points used for arthroscopic procedures (Fig. 1). ${ }^{18,19}$

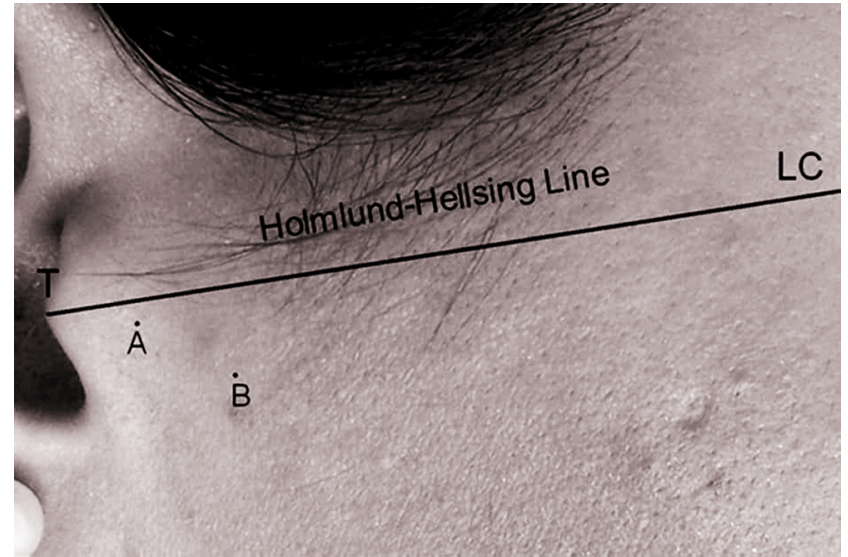

Fig. 1. Technique used for injections into the temporomandibular joint (TMJ) LC - lateral canthus; $T$ - tragus; $A$ - $10 \mathrm{~mm}$ from the middle of the tragus and $2 \mathrm{~mm}$ below the canthotragal line; B - $10 \mathrm{~mm}$ further along the canthotragal line and $10 \mathrm{~mm}$ below it.

A 19-gauge needle was then inserted into the upper joint cavity (UJC) at the glenoid fossa (point A), approx. $5 \mathrm{~mL}$ of Ringer's lactate was injected to distend UJC and some movements of the patient's mandible were performed for several minutes in order to mix Ringer's lactate with the synovial fluid (in our practice, we have found this to be a very important step, since without the proper mixing of the synovial fluid and Ringer's lactate solution, arthrocentesis does not proceed easily and effectively). Then, another 19-gauge needle was slowly and carefully inserted into the area of the articular eminence (point B) until the solution appeared in order to establish a free flow of the irrigation solution through UJC. The joint was irrigated with $100 \mathrm{~mL}$ of Ringer's lactate solution. The outflow needle was intermittently blocked in an attempt to get rid of the adhesions and to distend UJC by injecting under pressure, and the patient's mandible was gently moved to release the disk if it was stuck. At the end of lavage, the needles were removed in group I; $1 \mathrm{~mL}$ of HA was injected into the joint before removing the needles in group II and $1 \mathrm{~mL}$ of PRP was injected into the joint before removing the needles in group III.

During the follow-up phase, we did not administer any physical therapy or splint therapy.

Table 1. Comparison of the baseline values of the outcome variables between the study groups

\begin{tabular}{|c|c|c|c|c|}
\hline Variable & Control & HA group & PRP group & $p$-value \\
\hline Sample size & $n=10$ & $n=10$ & $\mathrm{n}=10$ & 1.000 \\
\hline $\begin{array}{l}\text { Sex } \\
\text { female } \\
\text { male }\end{array}$ & $\begin{array}{l}8 \\
2\end{array}$ & $\begin{array}{l}7 \\
3\end{array}$ & $\begin{array}{l}9 \\
1\end{array}$ & 0.945 \\
\hline Age [years] & 40.53 & 38.26 & 37.82 & 0.910 \\
\hline $\mathrm{MMO}[\mathrm{mm}]$ & $33.30 \pm 3.71$ & $31.60 \pm 4.55$ & $32.30 \pm 8.68$ & 0.960 \\
\hline Pain intensity [VAS] & $6.40 \pm 1.57$ & $5.60 \pm 1.43$ & $6.10 \pm 1.59$ & 0.897 \\
\hline Masticatory efficiency [VAS] & $3.60 \pm 1.38$ & $4.40 \pm 1.65$ & $3.90 \pm 1.48$ & 0.955 \\
\hline
\end{tabular}

Data for MMO, pain intensity and masticatory efficiency presented as mean \pm standard deviation (SD).

Control group - arthrocentesis only; HA group - arthrocentesis plus hyaluronic acid (HA); PRP group - arthrocentesis plus platelet-rich plasma (PRP); MMO -

maximum mouth opening; VAS - visual analog scale. 


\section{Platelet-rich plasma preparation}

Platelet-rich plasma was prepared according to the following protocol:

$1.5 \mathrm{~cm}^{3}$ of anticoagulant (3.8\% sodium citrate) was drawn into a 20-cubic centmeter syringe prior to taking blood and the inside walls were coated with the anticoagulant; $13.5 \mathrm{~cm}^{3}$ of venous blood was then drawn; afterward, the blood and the anticoagulant were mixed by slowly swinging the syringe and the gathered blood was transfused into a Ycellbio ${ }^{\mathrm{TM}}$ tube (Ycellbio Medical Co. Ltd., Seoul, South Korea).

The tube was then centrifuged with the following parameters: $3400 \mathrm{rpm}$ for $4 \mathrm{~min}$; and relative centrifugal force $(\mathrm{RCF})$ of $1.888 \times \mathrm{g}$.

After separation, $1 \mathrm{~mL}$ of pure platelet-rich plasma (P-PRP), without any leukocytes, was carefully aspirated into a separate syringe; immediately before injecting it into the joint, it was activated with $0.1 \mathrm{~mL}$ of $10 \%$ calcium chloride.

\section{Statistical analysis}

The software SPSS Statistics for Windows, v. 17.0 (SPSS Inc., Chicago, USA) was used for the data management and statistical analysis. The level of significance was set at 0.05 for all statistical tests.

The data fit normal distribution, as confirmed by the Shapiro-Wilk tests. The paired sample $t$-test was used to compare the mean values of the variables (MMO, pain intensity and masticatory efficiency) over time.
The one-way analysis of variance (ANOVA) was used to determine any differences in the mean values and standard deviations $(S D)$ of the variables (MMO, pain intensity and masticatory efficiency) between the 3 groups. When there was a significant difference among the means, the Šidák significant difference post-hoc test $(\alpha=0.05)$ was applied.

\section{Results}

In general, from a descriptive point of view, it was evident that the mean values of MMO, pain intensity and masticatory efficiency increased during the 9 months of follow-up for each of the 3 arthrocentesis techniques (Table 2).

No adverse effects or major complications were reported except for some minor complications associated with arthrocentesis, such as swelling of the preauricular region, caused by lateral extravasation of the irrigation fluid, which disappeared spontaneously after 2 or 3 days.

Statistically significant differences between the 2 periods (before treatment and at the 9-month follow-up) were observed for each of the values: MMO, pain intensity and masticatory efficiency. In the control group, they were $9.3 \mathrm{~mm},-3.8$ and 3.6, respectively; in the HA group - $13.8 \mathrm{~mm},-4.4$ and 4.0, respectively, and in the PRP group $-15.9 \mathrm{~mm},-5.4$ and 5.1 , respectively.

The one-way ANOVA revealed significant differences $(p<0.05)$ in the variables (MMO, pain intensity and masticatory efficiency) between the 3 groups (Fig. 2-4).

Table 2. Comparison of the mean values of maximum mouth opening (MMO), pain intensity and masticatory efficiency before the treatment and after 9 months of observation between the study groups

\begin{tabular}{|c|c|c|c|c|c|c|}
\hline Variable & Group & Period & Mean & $S D$ & Mean difference & $p$-value \\
\hline \multirow{6}{*}{$\begin{array}{l}\mathrm{MMO} \\
{[\mathrm{mm}]}\end{array}$} & \multirow{2}{*}{ control } & before treatment & 33.30 & 3.71 & \multirow{2}{*}{9.300} & \multirow{2}{*}{$0.002^{*}$} \\
\hline & & after 9 months & 42.60 & 4.32 & & \\
\hline & \multirow{2}{*}{ HA group } & before treatment & 31.60 & 4.55 & \multirow{2}{*}{13.800} & \multirow{2}{*}{$0.000^{*}$} \\
\hline & & after 9 months & 45.40 & 3.53 & & \\
\hline & \multirow{2}{*}{ PRP group } & before treatment & 32.30 & 8.68 & \multirow{2}{*}{15.900} & \multirow{2}{*}{$0.000^{*}$} \\
\hline & & after 9 months & 48.20 & 5.11 & & \\
\hline \multirow{5}{*}{$\begin{array}{l}\text { Pain intensity } \\
\text { [VAS] }\end{array}$} & \multirow{2}{*}{ control } & before treatment & 6.40 & 1.57 & \multirow{2}{*}{-3.800} & \multirow{2}{*}{$0.000^{*}$} \\
\hline & & after 9 months & 2.60 & 2.91 & & \\
\hline & \multirow{2}{*}{ HA group } & before treatment & 5.60 & 1.43 & \multirow{2}{*}{-4.400} & \multirow{2}{*}{$0.000^{*}$} \\
\hline & & after 9 months & 1.20 & 2.39 & & \\
\hline & PRP group & before treatment & 6.10 & 1.59 & -5.400 & $0.000^{*}$ \\
\hline \multirow{6}{*}{$\begin{array}{l}\text { Masticatory efficiency } \\
\text { [VAS] }\end{array}$} & \multirow{2}{*}{ control } & before treatment & 3.60 & 1.38 & \multirow{2}{*}{3.600} & \multirow{2}{*}{$0.000^{*}$} \\
\hline & & after 9 months & 7.20 & 2.74 & & \\
\hline & \multirow{2}{*}{ HA group } & before treatment & 4.40 & 1.65 & \multirow{2}{*}{4.000} & \multirow{2}{*}{$0.000^{*}$} \\
\hline & & after 9 months & 8.40 & 2.22 & & \\
\hline & \multirow{2}{*}{ PRP group } & before treatment & 3.90 & 1.48 & \multirow{2}{*}{5.100} & \multirow{2}{*}{$0.000^{*}$} \\
\hline & & after 9 months & 9.00 & 0.66 & & \\
\hline
\end{tabular}

\footnotetext{
* statistically significant.
} 


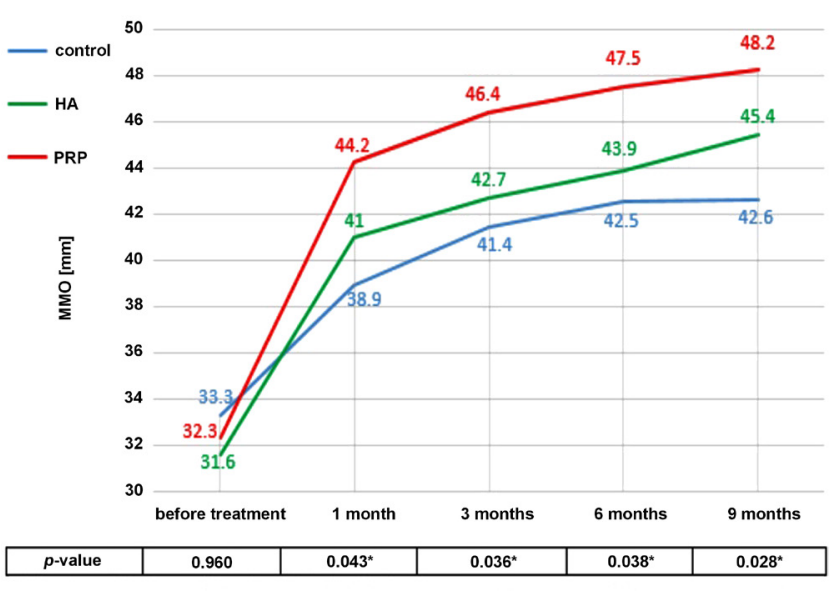

Fig. 2. Mean of maximum mouth opening at the time of the study * statistically significant.

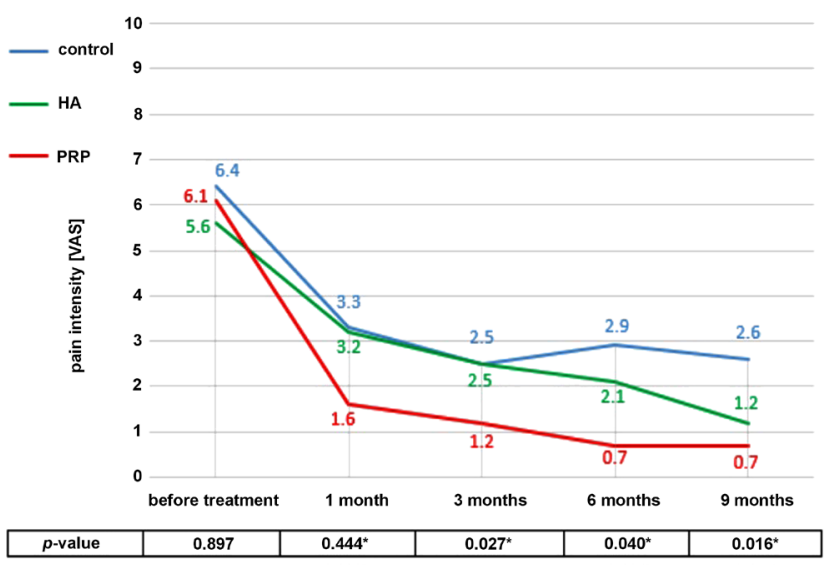

Fig. 3. Mean of pain intensity at the time of the study * statistically significant.

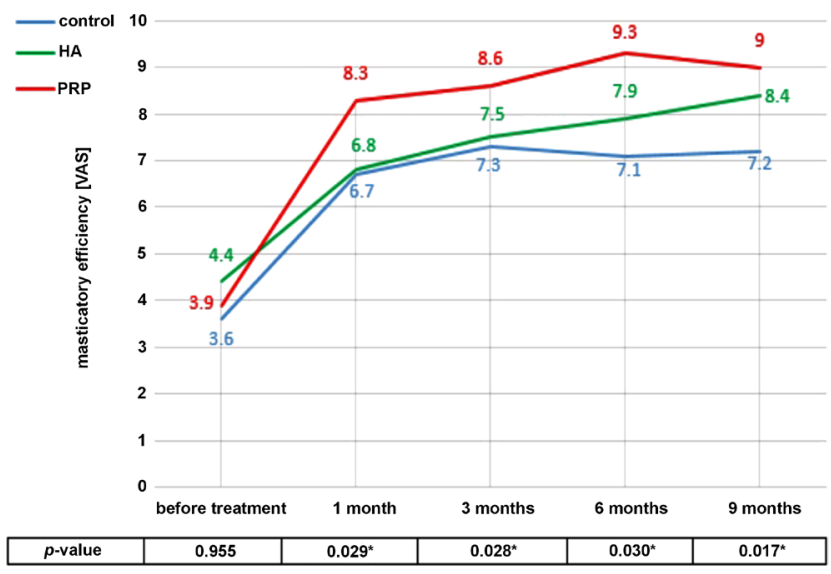

Fig. 4. Mean of masticatory efficiency at the time of the study ${ }^{*}$ statistically significant.

The increase in MMO in the PRP and HA groups was significantly greater than that in the control group $(p<0.05)$, whereas no significant difference was found between the PRP and HA group $(p=0.970)$ (Table 3$)$.
The pain intensity and masticatory efficiency results were significantly better in the PRP group than in the HA group or the control group $(p<0.05)$; at the same time, no significant differences were noted between the HA group and the control group $(p=0.700$ and $p=0.560$, respectively) (Table 3).

Overall, within the competitive framework, there has been improvement and consistency in the outcomes of the 3 techniques during the 9 months of follow-up.

\section{Discussion}

The substantial development of biochemical studies has drawn attention away from disk displacement theory ${ }^{20}$ to focus instead on the role of increasing friction between the contiguous parts of the joint in the incidence and exacerbation of TMDs. ${ }^{5}$

In the past, various kinds of conservative treatment were suggested to deal with TMDs, and when they failed, surgical disk repair and repositioning was the only available choice. ${ }^{21}$ However, there has been increased interest in arthrocentesis since improvement was observed in the clinical parameters of patients who had arthroscopy, even though their articular disks had not been operated on. ${ }^{9}$ In order to improve the results of arthrocentesis, the HA injection at the end of lavage was suggested due to the role of HA in the joint stabilization and nutrition, so this treatment might be useful in healing the lubrication system. ${ }^{22}$ The same is also true for PRP, which has recently been used as in orthobiologic adjuvant treatment. ${ }^{15}$

Thus, there was a need to clearly determine whether there was any benefit from injecting any drug after arthrocentesis or not, and which substance was the most effective.

In the present study, there were no statistical differences in age, sex or any of the baseline values of the outcome variables (Table 1). Consequently, the treatment technique used remained the main affecting variable. All treatment techniques resulted in significant clinical improvement in both VAS parameters (pain intensity and masticatory efficiency) and MMO. The mean differences for these values in the control group were $-3.8,3.6$ and $9.3 \mathrm{~mm}$, respectively; in the HA group, they were $-4.4,4.0$ and $13.8 \mathrm{~mm}$, respectively, and in the PRP group, they were -5.4, 5.1 and $15.9 \mathrm{~mm}$, respectively (Table 2 ). The improvement was gradual throughout the observation period. Two studies described minor adverse effects after the PRP application, such as pain during the injection, postoperative discomfort, ${ }^{15}$ or temporary swelling and soreness over TMJ, ${ }^{23}$ but in the present study, no adverse effects were recorded.

These results are consistent with the results of most previous studies. The positive outcomes might be explained by the direct effect of arthrocentesis, since washing out UJC eliminates inflammation mediators from the synovial fluid and causes a reduction in pain. Furthermore, the hydraulic distention during arthrocentesis increases 
Table 3. Comparison of the mean differences of the studied variables between the study groups during the observation period

\begin{tabular}{|c|c|c|c|c|c|}
\hline Variable & Group & Mean difference & SE & Absolute value & $p$-value \\
\hline \multirow{6}{*}{$\begin{array}{l}\mathrm{MMO} \\
{[\mathrm{mm}]}\end{array}$} & control & 9.300 & \multirow{2}{*}{1.955} & \multirow{2}{*}{4.500} & \multirow{2}{*}{$0.000^{*}$} \\
\hline & HA group & 13.800 & & & \\
\hline & control & 9.300 & \multirow{2}{*}{1.955} & \multirow{2}{*}{6.600} & \multirow{2}{*}{$0.000^{*}$} \\
\hline & PRP group & 15.900 & & & \\
\hline & HA group & 13.800 & \multirow{2}{*}{1.955} & \multirow{2}{*}{2.100} & \multirow{2}{*}{0.970} \\
\hline & PRP group & 15.900 & & & \\
\hline \multirow{6}{*}{$\begin{array}{l}\text { Pain intensity } \\
\text { [VAS] }\end{array}$} & control & -3.800 & \multirow{2}{*}{0.997} & \multirow{2}{*}{0.600} & \multirow{2}{*}{0.700} \\
\hline & HA group & -4.400 & & & \\
\hline & control & -3.800 & \multirow{2}{*}{0.997} & \multirow{2}{*}{1.600} & \multirow{2}{*}{$0.000^{*}$} \\
\hline & PRP group & -5.400 & & & \\
\hline & HA group & -4.400 & \multirow{2}{*}{0.997} & \multirow{2}{*}{1.000} & \multirow{2}{*}{$0.000^{*}$} \\
\hline & PRP group & -5.400 & & & \\
\hline \multirow{6}{*}{$\begin{array}{l}\text { Masticatory efficiency } \\
\text { [VAS] }\end{array}$} & control & 3.600 & \multirow{2}{*}{0.997} & \multirow{2}{*}{0.400} & \multirow{2}{*}{0.560} \\
\hline & HA group & 4.000 & & & \\
\hline & control & 3.600 & \multirow{2}{*}{0.997} & \multirow{2}{*}{1.500} & \multirow{2}{*}{$0.000^{*}$} \\
\hline & PRP group & 5.100 & & & \\
\hline & HA group & 4.000 & \multirow{2}{*}{0.997} & \multirow{2}{*}{1.100} & \multirow{2}{*}{$0.000^{*}$} \\
\hline & PRP group & 5.100 & & & \\
\hline
\end{tabular}

SE - standard error; ${ }^{*}$ - statistically significant.

the mandibular mobility by removing the intra-articular adhesions, getting rid of the negative pressure within the joint between the disk and the fossa space (vacuum effect), and thus reducing the mechanical obstruction.

Two things made it difficult to compare the results of our research with those of other studies. Firstly, it is a new study, since no previous ones have dealt with these 3 techniques simultaneously. Secondly, there is a wide variety of arthrocentesis techniques being used, in addition to different target groups for these techniques, such as patients with osteoarthritis, disk displacement, etc. Therefore, we tried to approach this discussion with the studies that most closely matched our study.

There are some discrepancies in the literature regarding the addition of medication after arthrocentesis. Alpaslan and Alpaslan examined the efficacy of arthrocentesis with and without the injection of sodium hyaluronate (SH) in the treatment of TMJ internal derangements. ${ }^{24}$ Although they found that both techniques improved the outcome parameters, arthrocentesis with the $\mathrm{SH}$ injection seemed to be superior to arthrocentesis alone. ${ }^{24}$ Cömert Kiliç et al. conducted a randomized clinical trial on adult patients with temporomandibular joint osteoarthritis (TMJ-OA). ${ }^{25}$ The patients were randomly treated with arthrocentesis alone (control group) or with initial arthrocentesis plus the PRP injection followed by 4 consecutive PRP injections (experimental group). Painless interincisal opening and lateral motion increased significantly only in the experimental group. Cömert Kiliç et al. suggested that arthrocentesis plus the PRP injection is superior to arthrocentesis alone. ${ }^{25}$
Lin et al. compared the efficacy of 2 approaches - arthrocentesis plus PRP and PRP alone - and concluded that arthrocentesis plus PRP demonstrated superior improvement in the jaw range of motion $<6 \mathrm{~mm}$ and pain when chewing foods. ${ }^{26}$

Zotti et al. presented a narrative review on the effects of arthrocentesis with PRP and PRP injections in the management of TMDs and compared them to those of arthrocentesis alone or with HA. They found encouraging results in terms of the effectiveness of the PRP therapy. ${ }^{27}$

In the present study, the increased MMO in the HA group was significantly greater than in the control group; our results for this parameter were similar to those obtained by Alpaslan and Alpaslan. ${ }^{24}$ This might be explained by the lubricating properties of HA, described in many studies by the term viscosupplementation - HA allows smoother movements within the joint with less friction, which results in improved mouth opening. This effect was not observed by Bergstrand et al., who compared arthrocentesis alone to arthrocentesis with the HA injection. ${ }^{28}$ They did not find a statistically significant difference between those groups. However, the results of that study cannot be thoroughly evaluated, as one very important issue was omitted, namely, the lavage volume of the perfusate for arthrocentesis was not mentioned in the study. ${ }^{28}$

Additionally, we found a significant increase in $\mathrm{MMO}$ in the PRP group as compared to the control group - a result which is consistent with that of Cömert Kiliç et al. ${ }^{25}$ This could be interpreted by the positive impact of growth factors, which restore the viscosity of the synovial fluid and lead to improvement in the jaw movement. 
On the other hand, we found that although the MMO result in the PRP group was better than in the HA group, there was no significant difference between the MMO values. This resembles the results obtained by Cömert Kiliç and Güngörmüş in their later randomized clinical trial conducted on adult patients with TMJ-OA. ${ }^{17}$ The patients were randomly divided into 2 groups: the PRP group patients underwent initial arthrocentesis plus the PRP injection followed by 4 consecutive PRP injections, whereas the HA group patients underwent 1 session of arthrocentesis plus the HA injection. No statistically significant differences were observed between the groups, so the researchers suggested that arthrocentesis plus PRP injections is not superior to arthrocentesis plus a single HA injection. ${ }^{17}$ Contradictory results were presented by Hegab et al., who enrolled patients with TMJ-OA in their study. ${ }^{15}$ One group received 3 injections of $1 \mathrm{~mL}$ of PRP, whereas the other received 3 injections of $1 \mathrm{~mL}$ of lowmolecular-weight HA. The PRP group exhibited better outcomes than the HA group in terms of the recurrence of pain and joint sounds, and an increased interincisal distance. ${ }^{15}$ This discrepancy may result from the different sample sizes - if our sample had been larger, we may have found a significant difference - and from the different arthrocentesis technique, since repeated PRP injections may be more effective than the single injection we applied, particularly because the target group in that study had degenerative joint disease.

The present study demonstrated that the pain intensity and masticatory efficiency scores among the PRP group were better than among the HA group and the control group. Only in this parameter did we find a consensus between our results and the findings of Hegab et al. ${ }^{15}$

There was no difference between the HA group and the control group in this respect; this is contrary to the results of Alpaslan and Alplaslan ${ }^{24}$ and may be due to the different solutions applied in the 2 studies. We used Ringer's lactate solution, whereas Alpaslan and Alplaslan applied a saline solution. Shinjo et al. suggested that Ringer's lactate solution is more compatible with the articular tissues than isotonic saline ${ }^{29}$; in addition, we think that Ringer's lactate solution makes the synovial fluid more viscous, which facilitates arthrocentesis and increases its effectiveness. Therefore, arthrocentesis in our study may have been more effective.

Based on the abovementioned results, we think that arthrocentesis plus PRP yields better outcomes in patients with arthralgia and dysfunction as the major complaint. When limited mouth opening is the primary symptom, there is no preference between PRP and HA as an additive after arthrocentesis. This agrees to a large extent with the results reported by Fernández-Ferro et al. ${ }^{30}$

Finally, it should be noted that the present study has some limitations. Firstly, our sample size was too small to achieve definitive conclusions. Secondly, our study included subjective estimations and observational compo- nents. Thirdly, our study was not designed as a doubleblind study, since the operator cannot be blinded to the material injected into the joint after arthrocentesis.

With the above limitations in mind, the present study has tried to shed some light on how to deal with TMDs, being one of the most difficult problems that oral and maxillofacial surgeons may encounter.

\section{Conclusions}

There is a preference for techniques including the injection of some agent, regardless of the agent used. Arthrocentesis plus PRP seemed to be superior to arthrocentesis plus HA or arthrocentesis alone, especially in patients with intense pain along with a regression in masticatory efficiency. However, additional studies with larger sample sizes may be valuable in determining the optimal technique for the treatment of TMJ disk displacement.

\section{ORCID iDs}

Mahmood Hasan Toameh (1) https://orcid.org/0000-0002-3733-3517 Issam Alkhouri (D) https://orcid.org/0000-0003-1957-6651

Mohammed Ammar Karman (D) https://orcid.org/0000-0001-5745-2540

\section{References}

1. Lazarin Rd, Previdelli IT, Silva Rd, et al. Correlation of gender and age with magnetic resonance imaging findings in patients with arthrogenic temporomandibular disorders: A cross-sectional study. Int J Oral Maxillofac Surg. 2016;45(10):1222-1228.

2. Young AL. Internal derangements of the temporomandibular joint: A review of the anatomy, diagnosis, and management. J Indian Prosthodont Soc. 2015;15(1):2-7.

3. Yeung RW, Chow RL, Samman N, Chiu K. Short-term therapeutic outcome of intra-articular high molecular weight hyaluronic acid injection for nonreducing disc displacement of the temporomandibular joint. Oral Surg Oral Med Oral Pathol Oral Radiol Endod. 2006;102(4):453-461.

4. Iturriaga V, Bornhardt T, Manterola C, Brebi P. Effect of hyaluronic acid on the regulation of inflammatory mediators in osteoarthritis of the temporomandibular joint: A systematic review. Int J Oral Maxillofac Surg. 2017;46(5):590-595.

5. Nitzan DW. The process of lubrication impairment and its involvement in temporomandibular joint disc displacement: A theoretical concept. J Oral Maxillofac Surg. 2001;59(1):36-45.

6. Türp JC, Komine F, Hugger A. Efficacy of stabilization splints for the management of patients with masticatory muscle pain: A qualitative systematic review. Clin Oral Investig. 2004;8(4):179-195.

7. Nicolakis P, Erdogmus CB, Kopf A, Nicolakis M, Piehslinger E, FialkaMoser V. Effectiveness of exercise therapy in patients with myofascial pain dysfunction syndrome. J Oral Rehabil. 2002;29(4):362-368.

8. Dionne RA. Pharmacologic treatments for temporomandibular disorders. Oral Surg Oral Med Oral Pathol Oral Radiol Endod. 1997;83(1):134-142.

9. Nitzan DW, Dolwick MF, Martinez GA. Temporomandibular joint arthrocentesis: A simplified treatment for severe, limited mouth opening. J Oral Maxillofac Surg. 1991;49(11):1163-1170.

10. Dimitroulis G, Dolwick MF, Martinez A. Temporomandibular joint arthrocentesis and lavage for the treatment of closed lock: A follow-up study. Br J Maxillofac Surg. 1995;33(1):23-27.

11. Salwowska NM, Bebenek KA, Żądło DA, Wcisło-Dziadecka DL. Physiochemical properties and application of hyaluronic acid: A systematic review. J Cosmet Dermatol. 2016;15(4):520-526. 
12. Altman RD, Manjoo A, Fierlinger A, Niazi F, Nicholls M. The mechanism of action for hyaluronic acid treatment in the osteoarthritic knee: A systematic review. BMC Musculoskelet Disord. 2015;16:321.

13. Fortier LA, Barker JU, Strauss EJ, McCarrel TM, Cole BJ. The role of growth factors in cartilage repair. Clin Orthop Relat Res. 2011;469(10):2706-2715.

14. Anitua E, Sánchez M, Nurden AT, et al. Platelet-released growth factors enhance the secretion of hyaluronic acid and induce hepatocyte growth factor production by synovial fibroblasts from arthritic patients. Rheumatology (Oxford). 2007;46(12):1769-1772.

15. Hegab AF, Ali HE, Elmasry M, Khallaf MG. Platelet-rich plasma injection as an effective treatment for temporomandibular joint osteoarthritis. J Oral Maxillofac Surg. 2015;73(9):1706-1713.

16. Schiffman E, Ohrbach R, Truelove E, et al.; International RDC/TMD Consortium Network, International Association for Dental Research, Orofacial Pain Special Interest Group, International Association for the Study of Pain. Diagnostic Criteria for Temporomandibular Disorders (DC/TMD) for clinical and research applications: Recommendations of the International RDC/TMD Consortium Network and Orofacial Pain Special Interest Group. J Oral Facial Pain Headache. 2014;28(1):6-27.

17. Cömert Kiliç $S$, Güngörmüş $M$. Is arthrocentesis plus platelet-rich plasma superior to arthrocentesis plus hyaluronic acid for the treatment of temporomandibular joint osteoarthritis: A randomized clinical trial. Int J Oral Maxillofac Surg. 2016;45(12):1538-1544.

18. McCain JP, de la Rua H, LeBlanc WG. Puncture technique and portals of entry for diagnostic and operative arthroscopy of the temporomandibular joint. Arthroscopy. 1991;7(2):221-232.

19. Tozoglu S, Al-Belasy FA, Dolwick MF. A review of techniques of lysis and lavage of the TMJ. Br J Oral Maxillofac Surg. 2011;49(4):302-309.

20. Stegenga B, de Bont LG, Boering G, van Willigen JD. Tissue responses to degenerative changes in the temporomandibular joint: A review. J Oral Maxillofac Surg. 1991;49(10):1079-1088.

21. Poliotis C, Stoelinga PJW, Gerritsen GW, Heyboer A. Long-term results of surgical intervention on the temporomandibular joint. Cranio. 1989;7(4):319-330.

22. Nitzan DW, Kreiner B, Zeltser B. TMJ lubrification system: Its effect on the joint function, dysfunction, and treatment approach. Compend Contin Educ Dent. 2004;25(6):437-438.

23. Hancı M, Karamese M, Tosun Z, Aktan TM, Duman S, Savaci N. Intraarticular platelet-rich plasma injection for the treatment of temporomandibular disorders and a comparison with arthrocentesis. J Craniomaxillofac Surg. 2015;43(1):162-166.

24. Alpaslan GH, Alpaslan C. Efficacy of temporomandibular joint arthrocentesis with and without injection of sodium hyaluronate in treatment of internal derangements. J Oral Maxillofac Surg. 2001;59(6):613-619.

25. Cömert Kiliç $S$, Güngörmüş $M$, Sümbüllü $M A$. Is arthrocentesis plus platelet-rich plasma superior to arthrocentesis alone in the treatment of temporomandibular joint osteoarthritis? A randomized clinical trial. J Oral Maxillofac Surg. 2015;73(8):1473-1483.

26. Lin SL, Tsai CC, Wu SL, Ko SY, Chiang WF, Yang JW. Effect of arthrocentesis plus platelet-rich plasma and platelet-rich plasma alone in the treatment of temporomandibular joint osteoarthritis: A retrospective matched cohort study (A STROBE-compliant article). Medicine (Baltimore). 2018;97(16):e0477.

27. Zotti F, Albanese M, Rodella LF, Nocini PF. Platelet-rich plasma in treatment of temporomandibular joint dysfunctions: Narrative review. Int J Mol Sci. 2019;20(2):277.

28. Bergstrand S, Ingstad HK, Møystad A, Bjørnland T. Long-term effectiveness of arthrocentesis with and without hyaluronic acid injection for treatment of temporomandibular joint osteoarthritis. J Oral Sci. 2019;61(1):82-88.

29. Shinjo H, Nakata K, Shino K, et al. Effect of irrigation solutions for arthroscopic surgery on intraarticular tissue: Comparison in human meniscus-derived primary cell culture between lactate Ringer's solution and saline solution. J Orthop Res. 2002;20(6):1305-1310.

30. Fernández-Ferro M, Fernández-Sanromán J, Blanco-Carrión $\mathrm{A}$, et al. Comparison of intra-articular injection of plasma rich in growth factors versus hyaluronic acid following arthroscopy in the treatment of temporomandibular dysfunction: A randomised prospective study. J Craniomaxillofac Surg. 2017;45(4):449-454. 